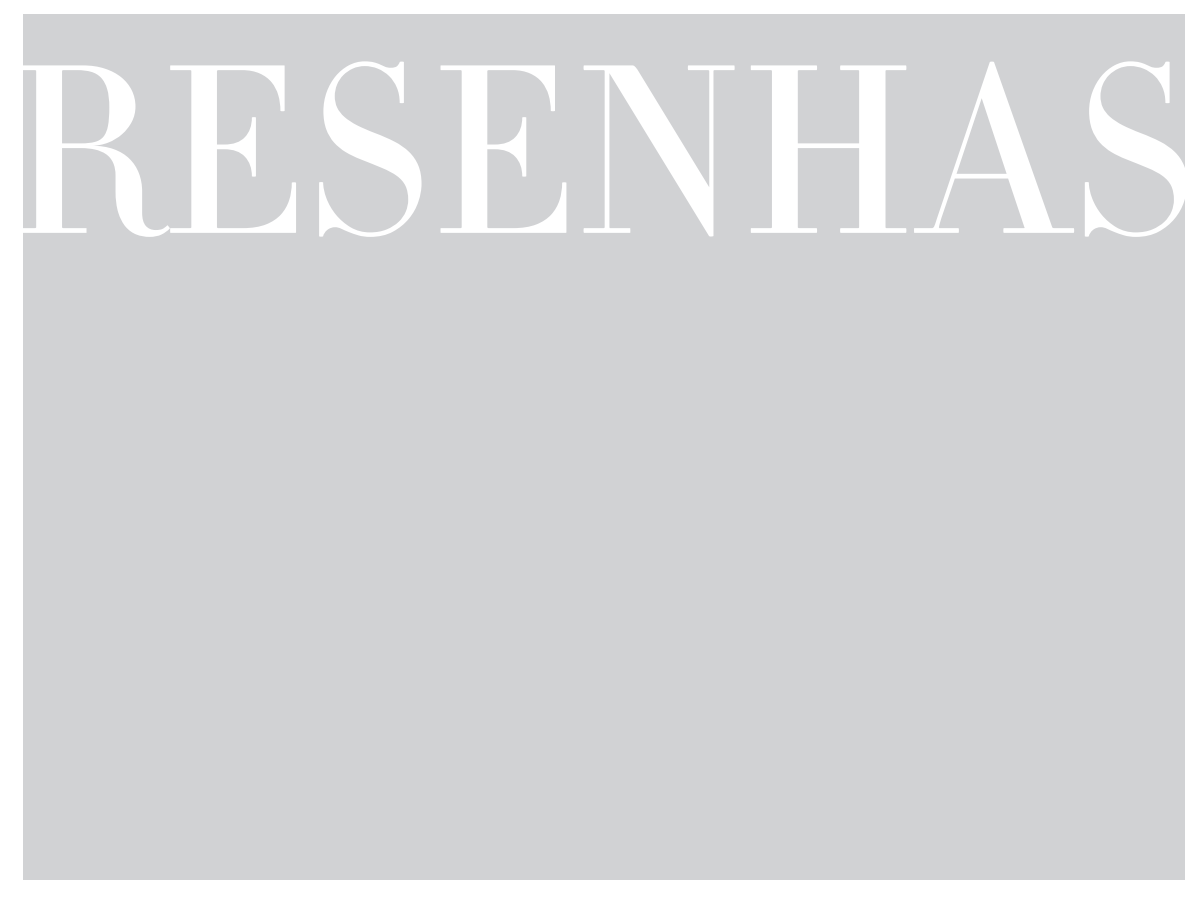

\title{
UM DIÁLOGO ENTRE A ANTROPOLOGIA E A EDUCAÇÃO A PARTIR DA PESQUISA ETNOGRÁFICA
}

https://doi.org/10.1590/198053144904

\author{
AMURABI OLIVEIRA'
}

GUEDES, Simoni Lahud; CIPINIUK, Tatiana Arnaud (Org.). Abordagens etnográficas sobre educação: adentrando os muros da escola. Rio de Janeiro: Alternativa, 2014. 219 p.

A educação constitui por excelência um campo profundamente interdisciplinar, no qual diversas áreas do conhecimento têm contribuído para seu processo de formação e consolidação, de tal modo que, dentro desse campo, têm se formado diversos outros "subcampos" do conhecimento, tais como a Sociologia da Educação, História da Educação, Filosofia da Educação, etc., que apresentam graus distintos de desenvolvimento em diferentes países.

No que concerne especificamente ao diálogo entre a Antropologia e a Educação, há de se reconhecer que, no caso brasileiro, esse ainda é um campo em processo de constituição (GUSMÃO, 2009), marcado por inúmeras tensões, especialmente no que diz respeito ao processo de incorporação da etnografia à pesquisa educacional. Esse desenho ainda cambaleante é visibilizado por algumas questões como: o parco número de linhas de pesquisa voltadas para a questão educacional nos programas de pós-graduação em antropologia (OLIVEIRA, 2015), a ausência de um grupo de trabalho voltado para a discussão antropológica no campo da 
educação nos eventos de educação, como nos encontros da Associação Nacional de Pós-Graduação e Pesquisa em Educação - ANPEd, etc.

Todavia, se, por um lado, é válido reconhecer que a presença de antropólogos pesquisando educação em programas de pós-graduação em antropologia é pontual no Brasil (OLIVEIRA; BOIN; BÚRIGO, 2016), por outro, é crescente o interesse pelo arsenal teórico e metodológico da antropologia para o desenvolvimento de pesquisas em educação, especialmente com a centralidade que as questões culturais têm assumido nas políticas educacionais, que perpassa desde o direito à educação diferenciada das populações indígenas até as ações afirmativas no ensino superior.

Nesse sentido, compreendemos que a coletânea Abordagens etnográficas sobre educação, organizada por Simone Guedes e Tatiana Cipiniuk, acaba por trazer uma contribuição incisiva à ampliação das discussões envolvendo a antropologia e a educação no Brasil, dando envergadura a uma literatura nacional ainda incipiente nesse tema.

A coletânea organiza-se em três partes: a primeira denominada “Olhares antropológicos sobre a educação no Brasil”; a segunda, "Escolas e ensino público”; e a terceira, “Abordagens etnográficas de mobilidades escolares: educação religiosa, alfabetização de adultos e os novos universitários”. Via de regra, os autores dessa coletânea são antropólogos no sentido estrito, em termos de formação acadêmica, porém são bastante heterogêneos no que diz respeito à vinculação institucional, parte vinculada a departamentos de Antropologia/Ciências Sociais e parte a faculdades de Educação, o que reflete a própria fragmentação institucional da Antropologia da Educação no Brasil.

Na primeira parte do livro, há dois textos de duas das mais proeminentes pesquisadoras sêniores nesse campo no Brasil: o primeiro, de Neusa Gusmão, intitulado “Trajetórias, percalços e conquistas da antropologia da educação no Brasil”, situa o leitor no percurso da antropologia junto às faculdades de Educação, mais especialmente aos cursos de formação de professores, indicando como a discussão própria da antropologia pode contribuir para a formação docente para a diversidade, ao mesmo tempo que indica os desafios do diálogo entre essas áreas, tanto no nível teórico quanto no institucional.

O segundo texto, "O universo da escola e dos profissionais da área da educação: tensões e proximidades entre a antropologia e a educação”, de Tânia Dauster, centra-se na problematização sobre o próprio olhar da antropologia e seu lugar no campo educacional, tomando como fio condutor a própria atuação da autora em um programa de pós-graduação em educação, indicando as possibilidades de construção de um olhar antropológico em pesquisas educacionais, que possibilitaria “a construção de um saber híbrido ou de fronteira, além de um olhar mais complexo sobre os fenômenos educacionais” (p. 34). 
Ambos os artigos confluem em dois pontos principais: a) o diálogo entre esses dois campos nem sempre é simples, porém encontra alguns pontos de proximidade a partir de categorias centrais como a de cultura; b) há o reconhecimento de que a antropologia pode oferecer à formação de docentes e de pesquisadores em educação ganhos significativos, sendo a pesquisa etnográfica um dos meios principais para tanto.

A partir da segunda parte do livro, temos artigos mais claramente assentados em textos etnográficos, sendo o primeiro deles "Educação X instrução: problemas do campo de prestações de serviço de ensino público", de Delma Pessanha Neves, no qual a autora examina a atuação de determinadas instituições sociais, explorando como no plano empírico se dá a ação dos professores, e o que orienta suas práticas, havendo basicamente dois modelos de ação: do professor ideal e do professor possível.

Também preocupadas com questões profundamente empíricas, Yvonne Maggie e Ana Prado, em "O que muda e o que permanece o mesmo nas escolas cariocas: culturas de gestão e as representações dos estudantes", trazem uma aproximação etnográfica com a realidade escolar, criando tipologias sobre as culturas de gestão, a do tipo burocrático-racional e a carismática, e indicando que a avaliação dos indicadores externos nem sempre coincidem com a avaliação realizada pelos estudos, suas famílias e a comunidade. Esse trabalho acaba por possibilitar uma compreensão mais ampla acerca do cotidiano escolar, e sobre como ele se operacionaliza a partir do ponto de vista dos "nativos", ${ }^{1}$ rompendo com análises mais abstratas da realidade escolar.

Nalayne Mendonça Pinto, partindo de uma pesquisa atrelada ao subprojeto do Programa Institucional de Bolsas de Iniciação à Docência - Pibid - de Ciências Sociais da Universidade Federal Rural do Rio de Janeiro - UFRRJ -, em "Juventude, conflitos e consensos: estudo de caso em duas escolas”, analisa como a questão da violência é percebida pelos jovens, considerando tanto o recorte de gênero quanto o tempo na escola. Problematiza ainda o papel da escola como mediadora de conflitos, partindo sempre do ponto de vista dos alunos, que apresentam uma visão crítica sobre o papel que essa instituição desempenha, assim como os docentes.

Em "A sociabilidade escolar à prova do reconhecimento no regime da philia: o (in) aceitável do insulto moral na relação entre pares”, de José Manuel Resende e Luís Gouveia, utiliza-se do diálogo com a Sociologia Pragmática para analisar questões que passam despercebidas em outras investigações, como a própria mudança de significado de elementos que são fundantes das sociabilidades dos jovens em deter-

minado contexto, mas que, no contexto escolar, passam a assumir um novo sentido.

A terceira parte do livro remete à abordagem etnográfica em diversas modalidades de ensino, começando pelo trabalho de Ana 
Paula Mendes de Miranda: “Escola: 'oficina das almas' ou dos cidadãos? Controvérsias contemporâneas em torno da educação moral religiosa em Portugal". Nesse artigo, encontramos um interessante debate acerca da religião no espaço público, o que é pensado justamente a partir da realidade escolar, o que tem sido pauta não apenas de pesquisas envolvendo a realidade portuguesa com também a brasileira. A escola, a partir da abordagem etnográfica, surge, portanto, como uma vitrine de questões mais amplas circunscritas no tecido social.

“"Matéria de caderno': jocosidade e evitação nas aulas de ensino religioso em uma escola pública”, de Bóris Maia, é um trabalho no qual a situação etnográfica na sala é trazida de modo bastante claro, destacando os elementos constitutivos do cotidiano das aulas de ensino religioso, fugindo de abordagens mais tradicionais que centram a análise sobre os conteúdos e as práticas pedagógicas. Apesar de o pesquisador perceber que as aulas apresentavam um claro viés proselitista, de forma surpreendente também é indicado que não houve conflitos envolvendo a questão religiosa nessas aulas. A abordagem acaba por inovar, ao trazer, através da etnografia, uma percepção de como os alunos desenvolvem suas próprias estratégias de resistência, na qual a jocosidade é a principal ferramenta.

Tatiana Cipiniuk, uma das organizadoras da coletânea, em “Alteridades e alfabetizações tardias”, assume como fio condutor a questão das desigualdades para pensar etnograficamente o processo de Educação de Jovens e Adultos. Ela realizou 55 entrevistas com alunos, em sua maioria migrantes vindo do Nordeste para o Rio de Janeiro, e encontrou entre eles uma das características mais marcantes: "a forma pela qual o privilegiado significado atribuído ao trabalho se manifesta como forma principal de investimento frente à unidade de ensino" (p. 191).

Por fim, também trazendo questões que tangenciam a questão da relação entre educação e desigualdade, Andréa Bayerl Mongim, em “Curso superior, status e prestígio social: percursos de escolarização de discentes beneficiários do Prouni”, parte de uma crítica das pesquisas que secundarizam a análise de concepções e práticas dos atores diretamente envolvidos nesse processo. Ela destaca como o projeto de ingressar no ensino superior se constitui nas trajetórias sociais desses sujeitos, tornando-se possível a partir de uma rede de apoios, apresentando-se como um projeto familiar. A inserção futura no mercado de trabalho sob melhores condições aparece como principal motivador, e, com isso, consequentemente, percebem a construção de movimento de ascensão social.

Apesar de se voltarem para temas tão distintos entre si, o que conecta todos esses trabalho é a percepção de que a abordagem etnográfica possibilita novos olhares sobre o objeto educacional, e, ainda que não se trate de arrogar uma exclusividade do uso da etnografia aos antropólogos, 
essa coletânea acaba por destacar a relevância do diálogo entre a antropologia e a educação para a realização de tal empreendimento.

Em que pesem as críticas que podem ser tecidas a uma compreensão mais rasa do uso da etnografia em educação, que recorrentemente indica a existência apenas de "pesquisas do tipo etnográfico" ou de “inspiração etnográfica” (OLIVEIRA, 2013), o presente trabalho assume um caráter afirmativo sobre tal uso, ainda que não esteja aqui reduzindo a etnografia a uma "ferramenta".

Acreditamos que, se uma das características particulares da pesquisa etnográfica é se voltar para aquilo que parece sem relevância para os demais pesquisadores (BARTH, 2000), essa coletânea visibiliza quão importante é esse exercício. As diversas pesquisas aqui apresentadas observam os processos educacionais a partir de novas perspectivas, que contribuem de forma ampla para o debate educacional, a partir de um conhecimento produzido em fronteira (DAUSTER, 2015), na interface entre a Antropologia e a Educação.

\section{REFERÊNCIAS}

BARTH, Fredrik. O Guru, o Iniciador e Outras Variações Antropológicas. Rio de Janeiro: Contra Capa Livraria, 2000.

DAUSTER, Tânia. An interdisciplinary experience in anthropology and education: memory, academic project and political background. Vibrant, v. 12, n. 2, p. 451-496, 2015.

GUSMÃO, Neusa Maria. Entrelugares: antropologia e educação no Brasil. Educação, v. 34, n. 1, p. 29-46, 2009.

OLIVEIRA, Amurabi. Por que etnografia no sentido estrito e não estudos do tipo etnográfico em educação? Revista FAEEBA, v. 22, n. 40, p. 69-82, 2013.

OLIVEIRA, Amurabi. Sobre o Lugar da Educação na Antropologia Brasileira. Temas em Educação, v. 24 , n. 1 , p. $40-50,2015$.

OLIVEIRA, Amurabi; BOIN, Felipe; BÚRIGO, Beatriz. A Antropologia, os Antropólogos e a Educação no Brasil. Revista Anthropológicas, v. 27, n. 2, p. 21-44, 2016. 